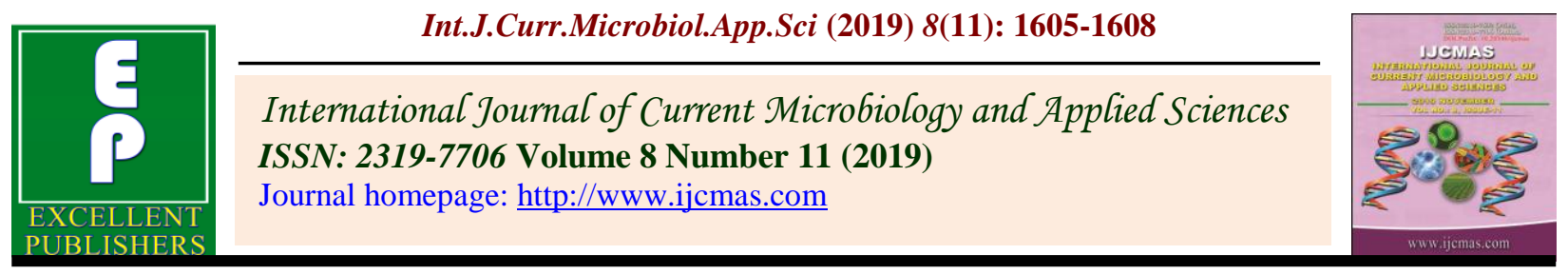

Original Research Article

https://doi.org/10.20546/ijcmas.2019.811.185

\title{
Seroprevalence of Brucellosis in Patients with PUO in North Karnataka District, India
}

\author{
Shilpa Gokale, S. S. Solabannavar*, Suresh Sonth, Anand Janagond, \\ Arati Bhurle, Anushka Devinkar and Amit Joshi
}

Department of Microbiology, S. Nijalingappa Medical College, Navanagar Bagalkot, India

*Corresponding author

Keywords

Brucellosis, Pyretic, RBPT, SAT

Article Info

Accepted:

12 October 2019

Available Online:

10 November 2019

\section{A B S T R A C T}

Brucellosis is one of the most important but neglected zoonoses worldwide and very common in India. Very few reports are available on the prevalence of human brucellosis in our region. Therefore a study was conducted to estimate the seroprevalence of brucellosis in patients with prolonged fever. The study was conducted from November 2017 to February 2018 at a tertiary care teaching hospital. A total of 196 sera samples from pyretic patients were collected and tested for anti brucella antibodies by RBPT and positive samples were further analysed by serum agglutination test (SAT) using standard Brucella abortus antigen from Indian Veterinary Institute, Izatnagar, UP, India. The seroprevalence of brucellosis among pyretic patients was estimated to be $2.55 \%$ with a titre of $\geq 1: 80$. The $2 \mathrm{ME}$ agglutination assay showed acute infection in $35 \%$ and remaining $65 \%$ were having chronic infection. Brucellosis among pyretic patients is common. Thus we emphasize the need for a routine screening of brucellosis in all patients presenting with PUO in our region.

\section{Introduction}

Human brucellosis is a very common zoonotic bacterial infection worldwide. The disease contributes significantly to economic losses in animal handlers $[1,2]$. The transmission to humans mostly results from the consumption of fresh milk and diary products prepared from unpasteurized milk such as soft cheeses, yogurt and ice cream [3,4,5]. Direct contact with infected animals can transmit infection in veterinarians, butchers, herdsmen and farmers $[6,7]$. Inhalation of aerosolized particles can cause infection in personnel working in microbiology laboratories [8,9].

The disease is more prevalent in the Mediterranean region, western Asia, parts of 
Africa and Latin America. A higher incidence of the disease can be expected in India, which has a major agrarian population who come in close contact with domestic animals[2,3,4]. The true incidence may be higher than the reported incidence due to misdiagnosis, largely due to lack of proper laboratory facilities in remote areas as well as poor exchange of information between veterinary and public health services $[10,11]$.

The prevalence of human brucellosis is difficult to estimate as many cases remain undiagnosed because either they are inapparent or due to their protean manifestations. Very few studies are available on the prevalence of human brucellosis in patients with PUO.

The main objectives of this study to estimate the seroprevalence of brucellosis in patients with PUO.

\section{Materials and Methods}

The study was conducted from November 2017 to February 2018 at H S K Hospital. A total of 196 serum samples were collected from prolonged fever cases. Patients with prolonged fever were defined as those with body temperatures higher than $380 \mathrm{c}$ on several occasions and lasting over a period of 3 weeks. Patients with proven and obvious causes were excluded from the study(tuberculosis, malaria). Detailed history was collected using a predesigned proforma.

Serum samples were analysed in 2 phases. In the first phase RBPT was performed. In the second phase, the seropositive samples were analysed by SAT. The reagents for the tests were obtained from the Indian Veterinary Reasearch Institute, Izzatnagar, Uttar Pradesh, India. Tests were performed as per the standard procedure.

\section{Results and Discussion}

Among the 196 patients with prolonged fever who were screened for brucellosis, 5 patients were positive by serological tests. The seroprevalence is estimated to be $2.55 \%$. The SAT assay showed acute infection in 2 patients and chronic infection in 3 patients. Highest seropositivity was seen in middle aged people and more common in males. Out of 5 positive cases, 2 were students, 2 were farmers and one was govt employee. Commonly associated symptoms were arthralgia and headache. Irregular fever was more commonly seen than continuous fever in seropositive patients. The distribution of seropositivity of brucellosis among patients are presented in Table 1.

The seroprevalence of brucellosis among patients with prolonged fever was estimated to be $2.55 \%$. Slightly lower prevalence of $2 \%$ was reported from Bangladesh [6] and seroprevalence of $0.8 \%$ was reported from Kashmir[8]. Majority of the infectious causes of prolonged fever will be tuberculosis, typhoid, malaria and viral infections.

Physicians routinely refer prolonged fever patients to diagnose these infections and neglect brucellosis as a cause of prolonged fever. Seroprevalence of $2.55 \%$ in our study indicates that all cases of prolonged fever should be screened for brucellosis.

Out of five positive cases 2 were farmers, 2 were students and one was govt employee. So the mode of infection in these students might be due to consumption of dairy products prepared from unpasteurized milk, as they were never exposed to livestocks in their life.

Brucellosis has remained largely undiagnosed due to diverse clinical manifestations, latent infections, low physician awareness and paucity of diagnostic facility. 
Table.1 Analysis of potential risk factors and clinical symptoms for brucellosis

\begin{tabular}{|c|c|c|}
\hline Factors & Tested & Positive \\
\hline Age group in years & & \\
\hline $\mathbf{2 - 2 0}$ & 43 & 1 \\
\hline $\mathbf{2 1 - 4 0}$ & 86 & 1 \\
\hline $\mathbf{4 1 - 6 0}$ & 67 & 3 \\
\hline Sex & & 2 \\
\hline Male & 73 & \\
\hline Female & & 2 \\
\hline No & 126 & 3 \\
\hline Yes & & \\
\hline Occupation & 23 & 2 \\
\hline Student & 34 & \\
\hline Day labour & 52 & \\
\hline Farmer & 43 & \\
\hline Buissness & 21 & 1 \\
\hline Housewife & 23 & \\
\hline Service & & \\
\hline Nature of fever & 154 & \\
\hline Irregular & 21 & \\
\hline Continuous & 21 & \\
\hline Rising and falling & & \\
\hline Arthrlgia & 42 & 2 \\
\hline No & 154 & \\
\hline Yes & 44 & \\
\hline Headache & 152 & \\
\hline No & & \\
\hline Yes & & \\
\hline & & \\
\hline
\end{tabular}

Thus we emphasize the need for a routine screening of brucellosis in all patients presenting with PUO in our region. RBPT and SAT tests are recommended as a screening test and should be confirmed by culture and sensitivity which is the gold standard test.

\section{References}

Agasthya A S, Isloor S, Prabhudas K. Brucellosis in high risk individuals. Indian J Med Microbiol 2007; 25: 2831
Alton GG, Jones LM, Pietz D E. Laboratory techniques in brucellosis. World Health Organ 1975; 1-163.

Anisur Rahman, A K M, Dirk Berkvens, Claude Saegermann, David Fretin, Noor Muhammad, Akram Hossain, Emmanuel Abatih. Seroprevalence of brucellosis in patients with prolonged fever in Bangladesh. J Infect Dev ctries 2016 ; 10 (9): 939-946.

Kadri S M, Rukhsana A, Laharwal MA, Tanvir M. seroprevalence of brucellosis in Kashmir (India) among 
patients with pyrexia of unknown origin. J Indian Med Assoc 98: 170-71.

Mantur B G and Amarnath S K. Brucellosis in India - a review ; J. Biosci 2008; 33: 539-547

Mantur B G, Akki A S, Mangalgi S S, Patil S V, Gobbur R H, Peerapur B V. Childhood brucellosis $\quad-\quad \mathrm{a}$ microbiological, epidemiological and clinical study. J trop Med hyg 2016; 83: 314-8.

Mantur B G, Amarnath S K, Shinde R S, Review of clinical and laboratory features of human brucellosis. Indian $\mathbf{J}$ Med. Microbiol 2007; 25: 188-202.

Mantur B G, Biradar M S, Bidri R C, Mulimani M S, Veerappa Kariholu P $\mathrm{L}$, et al., Protean clinical manifestations and diagnostic challenges of human brucellosis in adults: 16 years experience in an endemic area. J Med Microbiol 2006; 55: 897-903.

Pandit D P and Pandit $\mathrm{P}$ T. Human brucellosis: Are we neglecting an enemy at the backyard? OctoberDecember 2013; vol 6: issue 4: 350358.

Sharma H K, Kotwal S k, Singh D K, Malik M A, Kumar A, Rajagnalan, Singh M 2016 Seroprevalence of human brucellosis in \& around Jammu, India using different serological tests, veterinary world, 9(7): 742-746.

Thakur S D, Thapliyal D C. Seroprevalence of brucellosis in man. J Commun Dis., 2002; 34: 106-9.

\section{How to cite this article:}

Shilpa Gokale, S. S. Solabannavar, Suresh Sonth, Anand Janagond, Arati Bhurle, Anushka Devinkar and Amit Joshi. 2019. Seroprevalence of Brucellosis in Patients with PUO in North Karnataka District, India. Int.J.Curr.Microbiol.App.Sci. 8(11): 1605-1608. doi: https://doi.org/10.20546/ijcmas.2019.811.185 